\title{
Trabalho, adoecimento e rotatividade: investigação de uma central de teleatendimento a urgências
}

\author{
Work, sickness and turnover: \\ investigating an emergency service center \\ Trabajo, incapacidades médicas y rotación: \\ investigación de un central de teleatención a emergencias
}

\author{
Bruno Otávio Arantes*
}

\section{Resumo}

O teleatendimento tem apresentado um crescimento consistente. Somente em Belo Horizonte, nos dois últimos anos, foi o maior gerador de vagas no setor de serviços. Apesar de sua crescente importância econômica, estudos recentes estabelecem relação entre o trabalho no teleatendimento e o adoecimento, sendo a atividade considerada potencialmente danosa à saúde. Nesse sentido, o trabalho é compreendido como categoria social estruturante, na medida em que é produtor da condição humana e representa um eixo de sua historia. Este artigo tem por objetivo compreender os altos índices rotatividade e adoecimento em uma central de teleatendimento a urgências. A coleta de dados foi realizada por meio das observações do trabalho e entrevistas. A investigação teve como resultado principal que o adoecimento e a rotatividade estão associados às condições e a organização do trabalho. Nas conclusões são apresentadas algumas sugestões para a modificação desses elementos, visando reduzir, pelo menos em parte, esses índices.

Palavras-chave: adoecimento; rotatividade; teleatendimento; organização do trabalho. 


\section{Abstract}

Telemarketing has shown consistent growth. In the last two years, Belo Horizonte alone was the biggest generator of job vacancies in the service sector. Despite its growing economic importance, recent studies have established a relationship between telemarketing workers and illness, an the activity considered potentially harmful to health. In this sense, work is understood as a structuring social category, insofar as it produces the human condition and represents an axis of its history. The objective of this article is to understand the high rates of turnover and illness in a call center that deals with urgency. The data collection was done through observation of the work and via interviews. The main result of the investigation was that illness and turnover were associated with the conditions and organization of work. The conclusions present some suggestions for the modification of these elements, aiming to reduce, at least to some extent, these indexes.

Keywords: illness; turnover; telemarketing; work organization.

\section{Resumen}

La teleatención ha presentado un crecimiento constante. Sólo en Belo Horizonte, en los últimos dos años, fue el mayor generador de vacantes en el sector de servicios. A pesar de su creciente e importancia económica, estudios recientes han establecido una relación entre el trabajo en teleatención y el enfermarse, siendo así considerada, una actividad potencialmente perjudicial para la salud. En este sentido, el trabajo se entiende como una categoría social estructurante, en la medida en que es un productor de la condición humana y representa un eje de su historia. El objetivo de este artículo es comprender las altas tasas de rotación de personal y las incapacidades médicas en un centro de llamadas a urgencias. La recopilación de datos se realizó a través de las observaciones del trabajo y las entrevistas. El principal resultado de la investigación fue que las incapacidades médicas y la rotación se asociaron con las condiciones y la organización del trabajo. Concluyendo con algunas sugerencias para la modificación de estos elementos, con el objetivo de reducir, al menos en parte, estos índices.

Palabras clave: enfermedad; volumen de negocios; Teleatención; Organización de trabajo.

Ao longo dos últimos anos, o setor de teleatendimento tem apresentado um crescimento consistente. Somente em Belo Horizonte, entre Jan/2016 e Jan/2017, as funções de "Operador de Telemarketing Ativo e 
Receptivo", "Operador de Telemarketing Receptivo" e "Operador de Telemarketing Ativo" foram as maiores geradoras de vagas no setor de serviços (Ministério do Trabalho e Emprego, 2017).

Apesar da crescente importância do setor de serviços no cenário econômico, diversos autores (e.g., Echternacht, 2000; Rechenberg, Goulart, \& Roithmann, 2011) descrevem como a organização do trabalho está associada a certos tipos de patologias como as Lesões por Esforços Repetitivos (L.E.R.) e sintomas vocais, como a disfonia. Estudos que estabelecem uma relação entre o trabalho no teleatendimento e o adoecimento trazem como resultado que a organização do trabalho no setor é potencialmente danosa à saúde física e psíquica dos trabalhadores (Assunção \& Vilela, 2004; Le Guillant et al., 1956/2006; Venco, 2008).

Não se pode desconsiderar que as condições de trabalho em Call Centers transformaram-se substancialmente, sobretudo, pela introdução do sistema telemático (computador e linha telefônica). Porém, todas as pesquisas analisadas revelam uma organização do trabalho que sofreu poucas mudanças, desde a clássica pesquisa de Le Guillant et al. (1956). O estudo desses autores, intitulado "a neurose das Telefonistas" foi o precursor sobre o adoecimento entre estes trabalhadores. Nesse estudo e nos que se seguiram, são diversos os casos relatados de adoecimento em decorrência da atividade, em que se destacam como as maiores causas de sofrimento para os teleatendentes, algumas características da organização do trabalho: o script de atendimento (fraseologia padrão prescrita aos operadores); a média de tempo estipulado para a duração de cada atendimento, denominado Tempo Médio de Atendimento (TMA); a monitoração das ligações; a ausência de pausas durante o trabalho e a pressão por resultados.

Além disso, a intensificação do trabalho é um fator importante de desgaste para os trabalhadores. Essa intensificação é o resultado de algumas práticas, dentre elas, se destaca a temporização (pausa entre uma chamada e outra). Segundo Ricci e Rachid (2013) nas centrais do país, em 28,5\% dos casos, não existem pausas entre as ligações. 
Levando-se em consideração esses fatores, este artigo apresenta os resultados de um estudo realizado em uma central pública de atendimento a urgências/emergências. O objetivo foi identificar os motivos que estariam contribuindo para o adoecimento e a rotatividade no setor.

Foram utilizados os métodos de observação e entrevista no local de trabalho. O material obtido através desses métodos foi analisado à luz de alguns dos conceitos da clínica da atividade, tais como: estilo; atividade contrariada e gênero. (Clot, 2006).

Como resultado, é apresentado que existem diferenças significativas quanto às atividades desta central em relação à iniciativa privada, mas são mantidos alguns aspectos referentes à organização do trabalho. Por fim, apresentaremos as conclusões e algumas sugestões que podem ajudar a minorar os quadros de adoecimento e rotatividade.

\section{Trabalho e saúde}

O princípio ontológico que fundamenta este trabalho tem suas bases na centralidade do trabalho. Nesse sentido, a obra de Marx trata de uma ontologia do ser social, na qual o trabalho ocupa um lugar central ou fundante (Chasin, 1999). Assim, as relações sociais se tornaram possíveis somente na medida em que os homens tiveram de produzir seus meios de existência. Dessa produção e das trocas que efetivamente lhe são necessárias, tece-se todo intercâmbio entre os seres humanos e sua rede social. O trabalho, transformador da natureza e do próprio homem na sua autoprodução, distingue o ser humano dos animais: "O primeiro ato histórico desses indivíduos, por meio do qual eles se distinguem dos animais, não é o fato de eles pensarem, mas o de começarem a produzir seus meios de existência” (Marx \& Engels, 1846/1989, p.12).

Dentro dessa perspectiva, o psicólogo francês Yves Clot traz importantes apontamentos sobre o trabalho. Esse autor considera o trabalho de vital importância para o desenvolvimento psicológico e destaca sua função psicológica na medida em que "põe o sujeito à prova de suas obrigações práticas e vitais com relação ao outros e com relação ao mundo" (Clot, 2006, p.201). 
O trabalho é mais que a busca da sobrevivência, vital como processo histórico-social, central para o agir humano e para suas relações, sempre construído na atividade comum, do gênero estabelecido entre os trabalhadores e na construção, sempre em devir, da identidade. A função psicológica do trabalho vai além de um simples sentimento de utilidade. $O$ trabalho permite ao sujeito a troca com o social, seu lugar no mundo, como contribuinte de uma história que o ultrapassa e se estende além dele por meio das gerações (Clot, 2006).

A partir dessa perspectiva, a subjetividade tem um sentido histórico e social, pois na medida em que é construída e levada a termo efetivamente pelas relações de trabalho, não só com o trabalho em si, mas entre os sujeitos que o realizam, se efetiva a partir do gênero:

Pode-se defini-lo como um sistema flexível de variantes normativas e de descrições que comportam vários cenários e um jogo de indeterminação que nos diz de que modo aqueles com quem trabalhamos, como agir ou deixar de agir em situações precisas; bem como realizar as transações entre colegas de trabalho requeridas pela vida em comum organizada em torno de objetivos de ação (Clot, 2006, p. 50).

O gênero se estabelece a partir da atividade, orienta as ações dos sujeitos e mesmo sem a necessidade de ser repetido a cada tarefa, contribui para a construção da própria subjetividade. Sua apropriação individual, a possibilidade de assumir, no particular, um conhecimento coletivo, é denominada estilo, e traz uma contribuição de inventividade e renovação da atividade. O estilo pode ser definido como a possibilidade de modificação do gênero a partir da perspectiva individual, durante a ação. O gênero nunca é acabado, terminado, mas está sempre em transformação e desenvolvimento. O objeto da análise do trabalho seria compreender como se estabelecem as relações de gênero e sua configuração (Clot, 2006).

Neste estudo, busca-se a compreensão das ações dos trabalhadores, os métodos utilizados por eles que escapam às prescrições e possibilitam a realização de sua tarefa. Compreende-se por tarefa prescrita aquela marcada pelas orientações impostas ao trabalhador, numa tentativa de controlar os tempos e os movimentos, mas que nunca corresponde ao que é executado, 
que é a tarefa real (Daniellou, Laville, \& Teiger, 1989). Dentre as prescrições no setor de teleatendimento, se destaca o script de atendimento, composto por uma fraseologia padrão, que deve ser seguido ao pé da letra.

O conceito de atividade (Clot, 2006) neste trabalho assume um caráter diferente da tarefa real/prescrita formulada por Daniellou, Laville, e Teiger (1989). A atividade se relaciona não somente com o trabalho real, aquele realmente realizado pelo trabalhador, mas também é constituído pelas ações que o sujeito deixa de executar. São aquelas ações que, no momento, deixaram de ser levadas a termo para realizar o trabalho, dado os diversos tipos de exigências, seja por pressões temporais ou mesmo por regras que proíbem seu uso.

O esforço cognitivo de deixar de fazer como se intencionava, tem repercussões que não podem ser negligenciadas. Essa atividade contrariada é o que não se faz, que se poderia fazer, que se busca sem conseguir (Clot, 2006).

Segundo Lima (2002) é necessário uma investigação da situação real de trabalho e dos determinantes sociais e históricos relacionados ao adoecimento. Em busca dessas dimensões, neste artigo é utilizado o conceito de saúde proposto por Canguilhem (1966/2011). Saudável é o indivíduo capaz de ser normativo, de instituir novas normas. Segundo Canguilhem (1966/2011), “o que caracteriza a saúde é a possibilidade de ultrapassar a norma que define o normal momentâneo, a possibilidade de tolerar infrações à norma habitual e de instituir novas normas" (p.158).

Para Canguilhem (1966/2011) o limite entre o normal e o patológico é impreciso, mas apenas para indivíduos considerados simultaneamente, entretanto perfeitamente preciso para os sujeitos considerados individualmente. E a situação é um importante definidor dessa diferença. Ao se alterarem as circunstâncias para o indivíduo, o que em uma situação era perfeitamente normativo, pode se tornar patológico em outras condições, caso não ocorra nenhuma alteração. Para Canguilhem (1966/2011): “O indivíduo é que avalia essa transformação, porque é ele que sofre suas consequências, no próprio momento em que se sente incapaz de realizar as tarefas que a nova situação lhe impõe” (p.145). Segundo Canguilhem (como citado em Oliveira \& Jacques, 2006), "A doença não seria simplesmente 
desequilíbrio, mas também esforço para a construção de um outro equilíbrio possível; assim, ser sadio não equivaleria a ser normal em uma dada situação, mas poder instituir novas normas em condições diversas" (p.65).

\section{0 setor de teleatendimento}

Os trabalhadores dessa categoria, notadamente desde a década de 1950, quando ainda eram conhecidos como telefonistas e tinham condições de trabalho bem diferentes das atuais, foram estudados por diversos autores: Assunção e Vilela (2004); Barreto (2001); Castro, Campos, Assunção, e Lima (2006); Dejours (1987); Echternacht (2000); Le Guillant et al. (1956/2006); Marinho-Silva (2004); Mascia e Sznelwar (2000); Oliveira e Jacques (2006); Pacheco (2002); Sznelwar e Masseti (2000).

Passados mais de 50 anos, desde a pesquisa de Le Guillant et al. (1956/2006), a atividade é considerada patogênica, apesar de alguns avanços, tanto tecnológicos como da legislação a respeito. A atividade da antiga telefonista foi decomposta em diversas ocupações, reunidas em duas grandes famílias: Operadores de Telefonia e Operadores de Telemarketing, encontradas na Classificação Brasileira de Ocupações (CBO). As diversas funções de teleatendimento são agrupadas nestas duas famílias, que têm as seguintes descrições genéricas:

Operadores de Telefonia ( $\mathrm{CBO}$ 4222) Operam equipamentos, atendem, transferem, cadastram e completam chamadas telefônicas locais, nacionais e internacionais, comunicando-se formalmente em português e/ou línguas estrangeiras. Auxiliam o cliente, fornecendo informações e prestando serviços gerais. Podem treinar funcionários e avaliar a qualidade de atendimento do operador, identificando pontos de melhoria (Ministério do Trabalho e Emprego, 2002).

Fazem parte dessa família quatro ocupações: "telefonista" (CBO 4222-05); "Teleoperador" (CBO 4222-10); "Monitor de teleatendimento" ( $\mathrm{CBO}$ 4222-15) e Operador de rádio-chamada (CBO 4222-20). Os Operadores de Telemarketing ( $\mathrm{CBO}$ 4223) seriam aqueles que "Atendem usuários, oferecem serviços e produtos, prestam serviços técnicos especializados, realizam pesquisas, fazem serviços de cobrança e cadastramento de clientes, 
sempre via teleatendimento, seguindo roteiros e scripts planejados e controlados para captar, reter ou recuperar clientes" (Ministério do Trabalho e Emprego, 2002).

Essa família é subdividida em três ocupações: "Operador de Telemarketing Ativo e Receptivo" (CBO 4333-10), "Operador de Telemarketing Receptivo" (CBO 4333-15) e "Operador de Telemarketing Ativo" (CBO 433305). Castro et al. (2006) observam que esta nomenclatura multifacetada trata apenas do trabalho de atender clientes via telefone e, em todos os casos, via sistema telemático. Os autores defendem que as ocupações sejam mantidas dentro de uma mesma família, a de "Teleatendente".

Eles argumentam também que essa diferenciação entre funções equivalentes serve para retirar conquistas históricas da categoria e levam a uma maior precarização do trabalho. Uma das conquistas das telefonistas se refere à jornada reduzida de trabalho (seis horas). Até a publicação do Anexo II da NR-17, que regulamenta a jornada para a atividade, o Tribunal Superior do Trabalho indeferia os pedidos dos operadores de telemarketing pela jornada de seis horas, até o ano de 2011 (Tribunal Superior do Trabalho, 2002).

Barreto (2001) salienta que a função exercida pelo teleatendente é a mesma que era exercida pela telefonista, organizado sob as mesmas condições: fraseologia, controle, horários e monitoramento. Neste artigo, será utilizada a nomenclatura "Teleatendente" e em alguns casos, apenas atendente.

Nessa organização do trabalho se destacam alguns fatores que trazem sofrimento aos trabalhadores, tais como: Tempo Médio de Atendimento (TMA), o script de atendimento, a monitoria, estímulo à competição e controle sobre as pausas. O TMA se refere ao tempo médio de duração dos atendimentos ao cliente.

O estabelecimento desse TMA se dá à revelia dos atendentes e não se relaciona diretamente à qualidade da relação empresa-cliente, mas atende a fins econômicos estipulados pela empresa (Barreto, 2001; Ricci \& Rachid, 2013).

A Agência Nacional de Telecomunicações (ANATEL) é a responsável pela regulamentação do setor de telefonia. Por meio do Plano Geral de Metas 
de Qualidade (PGMQ), a ANATEL prevê que a prestadora de serviços telefônicos disponha aos usuários acesso contínuo, rápido e gratuito às centrais de informação e atendimento (Marinho-Silva, 2004). O regulamento do PGMQ define no artigo 16:

As chamadas destinadas aos serviços que utilizarem auto-atendimento ou necessitarem da intervenção de telefonistas deverão ser atendidas, em cada Período de Maior Movimento, em até 10 segundos, [...] em 95\% dos casos, a partir de 31/12/2005.

$\S 1^{\circ}$ - Em nenhum caso, o atendimento deverá se dar em mais de 35 segundos (Agência Nacional de Telecomunicações, 1998).

Para Marinho-Silva (2004) as regras definidas pela ANATEL são focadas nos aspectos econômicos, sem fazer referência à saúde dos trabalhadores envolvidos e o conceito de qualidade se vincula, basicamente, ao tempo de espera do consumidor. A redução dos tempos do serviço telefônico prestado acaba por justificar a definição, pelas empresas, de rígidos TMA's.

Na pesquisa de Le Guillant et al. (1956/2006) com as telefonistas ainda não havia a imposição de um TMA, mas o autor destacava que o modo como o rendimento necessário era calculado favorecia um "caráter penoso ao ritmo" de trabalho, pois esse era calculado a partir das médias de atendimento de algumas operadoras. Relata ainda que as operadoras ficavam "obcecadas" em atingir o ritmo imposto, por medo de serem mal avaliadas e perderem possíveis promoções (Le Guillant et al., 1956/2006, p.184).

Pacheco (2002) ao retomar o histórico da telefonia no Estado de Minas Gerais demonstra como era imposto o ritmo de trabalho sem a existência do TMA. Até 1984, as características tanto dos clientes como da tecnologia, não permitiam a imposição, pois o trabalho não dependia apenas da atividade realizada pela telefonista. Não era possível uma ligação direta entre o telefone de origem e o de destino. Todas as ligações interurbanas, por exemplo, dependiam da habilidade da telefonista em negociar com a telefonista de destino a conclusão da ligação. No entanto, já havia um controle sobre o tempo. A exigência de produtividade recaía sobre o tempo em que o cliente permanecia à espera de atendimento, que não poderia ser superior a 10 segundos. 
Com a introdução das novas tecnologias de informática e telecomunicações, a partir de 1994, foi possível exercer o controle sobre cada ligação e este tempo começou a ser denominado TMA (Pacheco, 2002). Para Mascia e Sznelwar (2000) existe uma ambiguidade em relação ao seu uso como parâmetro de produtividade, enquanto que para os teleatendentes entrevistados em sua pesquisa, ele servia apenas como base de comparação, para os supervisores, era uma meta a ser alcançada. Essa ambiguidade não foi bem esclarecida pelos autores, mas a visão dos supervisores é a que prevalecia.

O TMA prescreve aos operadores em quanto tempo o cliente deve ser atendido, mas não leva em consideração a diversidade da clientela, dos problemas gerados pela demanda e o tempo necessário para buscar informações no sistema telemático. O esforço cognitivo imposto pela tarefa gera um desgaste significativo, que se manifesta por meio de dores físicas, cansaço mental e fadiga (Barreto, 2001; Vilela, 2002).

O script de atendimento se refere à fraseologia que deve ser empregada por cada operador, de acordo com a atividade exercida e que tem seu conteúdo pré-definido para o diálogo com o cliente. Esse script contém as frases que devem ser ditas para saudar o cliente, para identificá-lo, responder à sua demanda e encerrar a ligação. Toda ligação é gravada e aleatoriamente "auditada". O anexo II da NR-17, proíbe a observância estrita do script (Ministério do Trabalho e Emprego, 2007). Contudo, essa é uma prática comum no setor.

Dejours (1987), que analisou o trabalho das telefonistas no Postes, télégrames et télecomunication, empresa estatal francesa que agrupa os correios, telégrafos e telefonia (PTT), demonstrou o sofrimento causado pelo controle do vocabulário, do número de frases a serem ditas e até mesmo do tempo para pronunciá-las. Para Pacheco (2002), a utilização do script traz um empobrecimento significativo da tarefa, já que restringe a atuação da telefonista, dado o curto período de tempo disponível para o atendimento. Essa restrição na comunicação se torna ainda pior em casos em que o atendimento é mais complexo. A autora também levanta que as exigências para que o teleatendente siga o script são enormes e esse é um dos aspectos mais cobrados na avaliação de desempenho. Le Guillant 
et al. (1956/2006) também verificaram que havia uma fraseologia padrão imposta às telefonistas para cada situação e que sua utilização era obrigatória, influenciando também em sua avaliação.

Mascia e Sznelwar (2000) alertam para a dificuldade envolvida na relação entre cliente e atendente, que se efetiva através da comunicação, cujo grau de complexidade é variável. Existem aqui possibilidades de conflito de várias ordens como demandas confusas por parte do cliente e conflitos entre o que quer o cliente e o que pode oferecer o teleatendente. Sznelwar e Massetti (2000) se referem ao script como uma "amarra" que impede o atendente de entender e fazer-se entender, o que dificulta o trabalho e traz sofrimento.

Echternacht (2000) avalia o problema a partir da diversidade individual e do meio social dos clientes que demandam serviços via telefone. O conteúdo prescritivo do trabalho tem baixa sensibilidade a tais fatores e é incapaz de fornecer a flexibilidade necessária ao conjunto das variáveis existentes na tarefa.

Em relação ao script de atendimento, Barreto (2001) aponta uma contradição identificada em sua pesquisa. Durante o treinamento, os teleatendentes são orientados a seguir a fraseologia, mas ao mesmo tempo a psicóloga responsável pelo setor os adverte no sentido de prestarem atenção na mesma e evitarem a robotização do atendimento. Se aceitarem a sugestão da psicóloga e não seguirem "à risca" o script, podem ser monitorados e punidos. Assunção e Vilela (2004) observaram que o script não restringe apenas os termos a serem utilizados, mas também a entonação de voz, de modo a moldar o afeto do sujeito, impedindo que seja gentil, sem prolongar o diálogo.

Outro fator mencionado na organização do trabalho em teleatendimento são as "monitorias" realizadas sobre os atendimentos. Como dito anteriormente, todas as ligações são gravadas e, através de um sistema de amostragem, são auditadas por funcionários treinados, os chamados "monitores". Cabe a esses profissionais avaliar a ligação, baseados em determinados critérios, que variam conforme a atividade do teleatendente e de 
empresa para empresa. Novamente, essa prática contraria o Anexo II, que prevê que as ligações só podem ser monitoradas mediante conhecimento do operador (Ministério do Trabalho e Emprego, 2007).

Esse procedimento existia na década de 1950. Sobre esse ponto, Le Guillant et al. (1956/2006) argumentavam que havia o sistema de "mesas de escuta" e que "as controladoras não concediam um momento de trégua às operadoras" (p. 185). A "escuta” tinha duas funções, controlar a distração e assegurar o uso correto da fraseologia imposta. Esta prática tinha como efeito um "ambiente sufocante" que resultava em "um sentimento de humilhação", no qual as telefonistas se sentiam "dirigidas como crianças" (Le Guillant et al., 1956/2006, p. 185). Pacheco (2002) relata que as telefonistas eram monitoradas constantemente, para garantir a qualidade das ligações. Essa escuta ocorria várias vezes ao dia e causava indignação nas telefonistas.

Mascia e Sznelwar (2000) consideram que essa monitoria é um fator de forte constrangimento para os teleatendentes. Principalmente, por que são feitas ao acaso e sem que tenham conhecimento de que são monitorados, o que gera insegurança e ansiedade. Dejours (1987) relatou que as telefonistas podem ser "escutadas" sem o saber. Esse procedimento gera "um verdadeiro terror por causa dessa escuta" (p.98), pois as notas ficam registradas e podem comprometer a avaliação das telefonistas.

A pressão por resultados no setor de teleatendimento é percebida através de alguns fatores. Um deles é o estímulo à competição entre os teleatendentes e entre as equipes. Essas últimas são denominadas células, sendo compostas de 20 atendentes, em média, e chefiadas por um supervisor.

Esse estímulo à competição é relatado por Le Guillant et al. (1956/2006). Devido ao esforço das telefonistas para atingir às médias impostas, nos períodos de baixo movimento, acabavam por brigar entre si para atender as chamadas. "No decorrer destas pequenas disputas, elas 'provocam ruídos nos fones das outras'; ora, tais ruídos representam um verdadeiro sofrimento para muitas delas" (p.184).

Barreto (2001) encontrou uma forma sutil, mas muito eficiente, de provocar a competição, o chamado projeto "reconhecimento", que premia individualmente os operadores e as células "mais eficientes". A "eficiência" 
é medida pelo TMA e não pela qualidade no atendimento e resolução de problemas. Sznelwar e Massetti (2000) consideram que esse estímulo à competitividade é um dos principais fatores de desgaste para os atendentes.

O controle da produtividade também se dá por uma rígida marcação das pausas. As pausas são controladas automaticamente pelo sistema e estão disponíveis para acesso dos supervisores. Até 1984, ainda não havia esse controle, mas Pacheco (2002) afirma que as telefonistas eram controladas, numa tentativa de eliminar os tempos mortos na jornada de trabalho.

Os achados de Barreto (2001) revelam que as pausas não são respeitadas, demonstrando a mesma tentativa de eliminação dos buracos na produção. De acordo com o anexo II da NR-17, as pausas deverão ser concedidas em dois períodos de 10 minutos, após 60 minutos trabalhados e antes dos últimos 60 da jornada. Esses intervalos devem ser concedidos sem prejuízo do intervalo de 20 minutos para repouso e alimentação. Além disso, o tempo em efetiva atividade não pode ultrapassar 6 horas diárias (Ministério do Trabalho e Emprego, 2007). Sznelwar e Massetti (2000) também se referem à insuficiência das pausas como fator que gera sofrimento.

Todos os fatores utilizados para o controle da produtividade no setor de teleatendimento levam a uma significativa auto-aceleração da atividade. Le Guillant et al. (1956/2006) demonstravam sua preocupação com a aceleração das cadências em 1956, que estaria relacionada com os modos de remuneração, como as notas por desempenho, por exemplo. Echternacht (2000) demonstra a importância de se entender esse fenômeno como expressão do sofrimento no trabalho.

Nesse sentido, pode-se considerar que desde a década de 1950 a organização do trabalho no setor não se alterou, substancialmente, embora as condições de trabalho tenham se modificado bastante. Os autores citados encontraram os mesmos problemas. A introdução de novas tecnologias, como o sistema telemático, permitiu que a atividade fosse realizada de forma mais ágil. Em alguns setores, como o de informações, o conteúdo da atividade se tornou ainda mais pobre, já que parte da informação é fornecida através de uma gravação eletrônica (Pacheco 2002). 


\section{MÉTODO}

Neste artigo busca-se localizar a proposta de trabalho no campo, sobre bases essencialmente empíricas junto aos trabalhadores no exercício de suas tarefas - a partir do método de observação do trabalho. Por meio dessa abordagem, o propósito foi o de compreender as condições e a organização do trabalho dos teleatendentes, bem como o sentido que atribuem à sua atividade, como vivenciam as pressões e quais são suas estratégias de enfrentamento.

A observação clínica do trabalho consiste na observação direta das tarefas executadas pelos trabalhadores e na escuta de seus depoimentos espontâneos, interferindo o mínimo possível em sua rotina de trabalho. Em outras palavras, o objetivo foi compreender como o sujeito realiza suas tarefas, as dificuldades que encontra e as estratégias que utiliza para lidar com elas.

Durante a investigação, considerou-se que o trabalhador é quem mais conhece seu próprio trabalho e por isso foi privilegiado o contato direto interferindo o mínimo possível em sua rotina de trabalho. Sobre as possibilidades dessa forma de investigação da realidade de trabalho, Lhuilier (2007) afirma que:

Tal procedimento pode privilegiar a investigação do trabalho real, do trabalho organizacional, do coletivo dentro de seus meios, a formalização da experiência informal para restituir sua transmissão, a constituição de um saber prático [...], uma elaboração do sofrimento no trabalho e uma possibilidade de deixar transparecer os impasses das estratégias coletivas de defesa (p. 72, tradução do autor).

Trata-se de uma posição exigida na pesquisa de campo, que solicita do investigador uma atitude de recusa a qualquer a priori, de modo a ter acesso ao que efetivamente ocorre na situação de trabalho. Além disso, abandona a posição de expert, passando a construir um saber sobre a situação de trabalho junto com os próprios trabalhadores.

O pesquisador rompe com essa posição de saber ou de expertise (proposições, conselhos, sugestões) para se empenhar dentro de uma relação de cooperação com os sujeitos autores de um projeto comum. O 
pesquisador se reconhece, como os outros atores, comprometidos dentro de um mesmo processo: trata-se de fazer compreensível e compreender agindo (Lhuilier, 2007, p. 64, tradução do autor).

Os sujeitos da pesquisa não são tomados apenas como objetos passivos de investigação, mas como sujeitos comprometidos e capazes de refletir sobre seu trabalho. A posição adotada pelo pesquisador é a da colaboração, permitindo que o saber do trabalhador se apresente. A partir das observações, os próprios trabalhadores, por meio da presença de um terceiro (o pesquisador), podem refletir sobre suas práticas. Essa reflexão não é vazia de sentido, mas permite uma análise crítica que resulta na busca de soluções adequadas para os problemas enfrentados. Não se trata aqui de ignorar o conhecimento sobre as questões teóricas, mas relativizá-las, permitindo a abertura para outro saber, advindo da prática única que cada situação de trabalho engendra.

Desse modo, para a análise da organização do trabalho (horários; turnos; pausas para descanso e alimentação; hierarquias; formas de avaliação; obrigatoriedade do script de atendimento; conteúdo do trabalho; etc.) considera-se fundamental compreender a percepção dos trabalhadores em relação às políticas de pessoal; regras explícitas; implícitas; meios de comunicação; missão da instituição; valores; relações entre chefia e subordinado e entre colegas.

Os instrumentos utilizados foram as observações da atividade dos teleatendentes enriquecidas com entrevistas realizadas no próprio local, com a finalidade de esclarecer aspectos obscuros. Com o objetivo de compreender melhor a interação entre os usuários e os constrangimentos que a tarefa apresentava (por exemplo, as informações prestadas pelos solicitantes e os trotes) realizou-se ainda a escuta das ligações.

Essas observações foram realizadas durante um período de oito meses, em todos os turnos de trabalho. Duas vezes por semana, o trabalho dos teleatendentes era observado por duas horas, sendo registradas todas as impressões em diário de campo. Cada trabalhador foi informado da pesquisa e de sua finalidade, do caráter voluntário de sua participação e da garantia de anonimato. $O$ contrato de participação na pesquisa foi realizado por meio de Termo de Consentimento Livre e Esclarecido (TCLE), assinado 
por todos os voluntários, resguardada a possibilidade de desistência a qualquer momento. O trabalho, que fazia parte de outros estudos realizados no mesmo período foi aprovado pelo comitê de ética interno da instituição.

\section{RESULTADOS E DISCUSSÃO}

De modo conciso, a atividade de teleatendente no setor consiste em receber as ligações feitas para a central publica de urgência e emergência, realizar a triagem das ligações, definir se o caso é de responsabilidade desta central ou de outro órgão do Estado e registrar a demanda.

A triagem é realizada em duas etapas subsidiadas por softwares específicos. Para atender a ligação, deixá-la em espera (caso seja necessário consultar o supervisor) e travar o sistema para não receber novas ligações, o teleatendente utiliza o programa denominado "Interface". Caso a solicitação componha a atividade fim da central, o teleatendente deve registrar a chamada. Em outras palavras, preencher um cadastro no segundo programa, denominado Controle de Atendimento e Despacho (CAD). A chamada salva no CAD é automaticamente repassada para o sistema de outro profissional, que por sua vez, é responsável por definir o tipo de veiculo a ser designado para o local da ocorrência.

Existem similaridades entre o trabalho nessa central e aquele realizado em outros centros de teleatendimento, mas diferenças substanciais, não apenas em relação ao conteúdo das tarefas, mas também em relação à organização do trabalho em geral que devem ser sublinhadas.

O Tempo Médio de Atendimento (TMA) é determinado enquanto parâmetro. Na prática, os supervisores não exercem qualquer pressão para seu cumprimento, portanto, não aparece como uma meta a ser atingida.

O script orienta a saudação inicial. O restante do diálogo entre o teleatendente e o solicitante pode ser feito com certo grau de autonomia, pois manifestações de afeto, rancor ou agressividade são proibidas.

O monitoramento é realizado apenas em ligações que excedam cinco minutos. Esse controle não é realizado pelo monitor, figura inexistente 
nesse contexto. Cabe ao supervisor, segundo os relatos dos trabalhadores, verificar se existe alguma dificuldade em relação à "geração da chamada" e também evitar ligações particulares.

A pressão por resultados incide sobre o conteúdo da tarefa, pois se trata de um serviço que, a princípio, deve ser solicitado apenas em situações de emergência. Nesse sentido, se relaciona à expectativa de preenchimento correto do endereço do sinistro (desastre, acontecimento trágico que acarreta grandes perdas materiais) no sistema. Essa pressão não está relacionada a metas de produtividade e, por consequência, não existe um estímulo à competição.

As pausas observam as orientações da NR-17 - Ergonomia (Ministério do Trabalho e Emprego, 2007). Não há um controle extremado sobre os chamados "tempos mortos" da produção, que incluem, por exemplo, o tempo destinado à satisfação das necessidades fisiológicas dos trabalhadores.

Foi descrito anteriormente alguns aspectos relativos à triagem efetuada pelos teleatendentes. Agora, serão analisadas algumas questões relativas às ligações, principalmente os constrangimentos de diversas ordens originados dos trotes, que chegam a 35\% das ligações efetuadas para a central.

Esses dados são similares aos apresentados por Castro et al. (2006) que encontraram $42 \%$ de trotes entre as chamadas realizadas para outra central de atendimento a emergências. Essas ligações ocupam as linhas telefônicas e dificultam o acesso da população aos serviços.

A maioria dos trotes é realizada por crianças que, geralmente, não dizem nada, mas em alguns casos, ofendem. Nessas circunstâncias, as reações dos atendentes são variadas. Alguns interrompem a ligação assim que percebem que se trata de trote e outros falam com o infrator, alertando que a prática é crime e prejudica o atendimento da população. Foi presenciada pelo pesquisador uma situação em que ocorreram 16 trotes, em um mesmo ramal, em menos de duas horas. Quando há um grande volume de ligações, o trote perturba o atendente que se sente irritado e frustrado.

Mas existe uma modalidade de trote mais complexa, segundo os atendentes, que busca informar um sinistro inexistente. Nesses casos, o 
atendente utiliza algumas estratégias para verificar a veracidade da ligação. A primeira consiste em se atentar para os sons e os ruídos no local da chamada. Os trabalhadores explicam que quando a chamada é real, pode-se ouvir o barulho das pessoas no local, a conversa entre elas.

Fazer diversas perguntas ao solicitante, observando possíveis contradições nas informações prestadas também é uma estratégia bastante utilizada. O software Interface é um auxílio importante ao teleatendente para a conferência do número do telefone que origina a chamada com aquele informado pelo solicitante. Confirmado corretamente, esse é um indício de que não se trata de trote.

Essas estratégias são ferramentas importantes para a realização da atividade. Os teleatendentes afirmam que aprendem isso na prática, com o auxílio dos colegas mais experientes e dos supervisores. Trata-se, portanto, de um bom exemplo de como funciona o gênero da atividade (Clot, 2006).

Para realizar suas atividades de atendimento de ligações e triagem, os trabalhadores desse setor devem respeitar os 35 artigos das Normas Gerais de Ação (NGA) que tratam das "competências, procedimentos e condutas operacionais no teleatendimento”. Essa norma prescreve, basicamente, a organização do trabalho: estar uniformizado; verificar o equipamento; ajustar a altura da cadeira e do micro; atender a ligação com os dizeres: "Emergência, nome, bom dia, boa tarde, boa noite"; ouvir atenciosamente o solicitante, dentre outros.

Destaca-se a regra que trata diretamente de um aspecto da organização do trabalho essencial ao desenvolvimento da atividade: "Evitar conversas paralelas no local de trabalho". Foi identificado durante as observações e entrevistas que, mesmo nos horários considerados de "pico", o diálogo entre os trabalhadores acontece normalmente, sem prejuízo para a efetivação da tarefa. O conteúdo das "conversas paralelas" versa sobre os mais variados temas, dentre eles as escalas de trabalho, trocas de horário/ turno, ocorrências que aconteceram e o esclarecimento de dúvidas relativas aos atendimentos. As conversas trazem em seu teor diversos aspectos referentes ao conteúdo da atividade e a situações-problema que auxiliam os teleatendentes na realização de suas tarefas. Conclui-se que essas conversas são necessárias para compartilhar as experiências adquiridas em 
cada nova situação e lidar com as imprevisibilidades, para o aprendizado dos teleatendentes novatos, para a própria organização do trabalho e para a construção e o fortalecimento do gênero da atividade (Clot, 2006). Se a regra que proíbe as conversas paralelas dificulta ou impede a construção do gênero da atividade, os trabalhadores criam estratégias para burlar, ainda que de modo parcial, essa prescrição.

Pode-se observar a questão do gênero da atividade e sua importância quando há uma chamada considerada por eles de "destaque", devido às suas proporções ou existência de vítimas. O usual é que mais de uma pessoa entre em contato com a central ao mesmo tempo. Nessas situações, os atendentes se levantam na cabine e dizem a seguinte frase: "alguém está gerando (natureza do evento), no (endereço da ocorrência)?”. Esse tipo de informação, assim compartilhada por todos os atendentes, é uma estratégia importante para evitar a duplicidade de empenho de recursos em uma mesma ocorrência.

O treinamento dos teleatendentes é realizado durante 45 dias em média, antes do início de suas atividades. Na primeira etapa, fazem visitas à central para observar as atividades operacionais e aprender conceitos sobre telemarketing e o sistema informatizado. Em seguida, ficam cerca de duas semanas acompanhando o trabalho de um colega mais experiente, antes de iniciar o atendimento. Esse período de aprendizado é denominado "carrapato”. É quase unanimidade entre os teleatendentes que o aprendizado da atividade se dá pela prática e pelo apoio dos colegas. Muitos afirmam que o treinamento não oferece tudo o que necessitam para iniciar o trabalho de teleatendimento. E isso seria praticamente impossível, uma vez que é sempre muito mais eficaz o aprendizado "pela experiência", facilitado pela atuação dos colegas de trabalho, através da rememoração e reapropriação do gênero da atividade, que se concretiza a partir do estilo de cada atendente e na confrontação com o "novato".

A NGA normatiza as escalas e as folgas, sendo objeto de queixas constantes por parte dos teleatendentes que consideram que ela não permite o descanso efetivo e interfere em seu convívio social. De fato, tudo indica que a escala não é elaborada pensando no descanso eficaz. A preocupação da administração parece ser a de manter um efetivo suficiente para atender à 
demanda. Frequentemente, um grupo de teleatendentes cumpre sua escala de trabalho em feriados consecutivos, como aqueles que trabalham nos feriados de Natal e Ano Novo há quatro anos, sendo impossibilitados de comemorar essas datas com seus familiares. Embora a preocupação com o atendimento da população seja essencial, os próprios atendentes acreditam que a escala pode prever períodos de descanso com maior qualidade, sem comprometer o número de trabalhadores responsáveis pelo atendimento.

Até aqui, leva-se em consideração as prescrições regulamentadas pela NGA. Mas, nesse setor, existem outras normas criadas pela administração. A primeira é um sistema de premiação e punição de faltas denominada "seguidinha” e, a segunda, é um impedimento de um sistema de auto-regulação dos trabalhadores e de suas folgas. Ambas foram instituídas para a redução do absenteísmo, incidem uma sobre a outra, e estabelecem correlação com a saúde do trabalhador.

Destaca-se que a escala de trabalho consiste em quatro dias de serviço para um de folga e uma vez por mês o teleatendente tem o direito ao sábado e domingo de descanso. A "seguidinha" consiste em uma folga sábado/ domingo extra por mês, desde que o trabalhador não tenha nenhuma falta (mesmo justificada) durante o mês precedente. Se algum teleatendente não puder comparecer ao trabalho por motivos médicos, mesmo entregando um atestado, perde o direito à "seguidinha", ainda que não tenha aquele dia descontado em sua folha.

Cabe destacar que a administração proibiu que os teleatendentes deixassem o trabalho mais cedo ou chegassem mais tarde para consultas médicas, devendo fazer isso apenas em seus dias de folga. Todavia, muitos atendentes dependem exclusivamente do Sistema Único de Saúde (SUS), pois a empresa contratante oferece plano de saúde apenas com co-participação e a maioria não pode arcar com os custos das consultas e dos exames. Dessa forma, encontram dificuldade em agendar o atendimento para os dias de folga. Essa proibição era contornada pela cooperação entre os trabalhadores que trocavam entre si os dias de folga para realizar consultas médicas e atividades de lazer, como viagens familiares, sendo, portanto, um importante meio de regulação. 
As trocas consistem em acordos feitos entre os trabalhadores, do mesmo turno ou de turnos diferentes, sendo um atendente substituído por outro. Eram permitidas desde que não prejudicassem o número de teleatendentes em serviço e foram limitadas a duas por teleatendente, no mês.

Se o efeito desejado com essas medidas era o de reduzir os índices de absenteísmo, foi percebido por meio das observações que elas resultaram em "presenteísmo". Para não perder a folga extra, os trabalhadores comparecem ao trabalho mesmo apresentando alguns sintomas, inclusive de depressão e fazendo uso de medicamentos. Tal prática pode apresentar resultados negativos para os trabalhadores, considerando que a exposição ao ambiente pode agravar os quadros apresentados.

Nessa central, a principal tarefa do teleatendente é o "registro da chamada”. Nessa operação, o atendente deve digitar algumas informações para a correta localização do sinistro e despacho das viaturas. Sobre esse aspecto, foram relatadas diversas divergências entre os supervisores do teleatendimento sobre os casos que exigem atuação da instituição. Os casos que suscitam maiores divergências são os relativos aos casos de prevenção e atendimento clínico. Durante um mesmo turno de trabalho, os teleatendentes podem receber duas ou mais orientações distintas para casos idênticos. Eles se referem a essa indefinição nas regras como "falta de padronização". Um deles comentou o assunto: "às vezes há uma situação e seis respostas diferentes, aí, você escuta críticas por ter agido de uma forma que não seria encarada como problema por outra equipe de supervisores". Em decorrência os atendentes têm de interromper seu trabalho para consultar seu supervisor.

De um modo geral, a atividade de teleatendimento neste setor difere da iniciativa privada, principalmente em relação ao conteúdo da tarefa. Ao contrário do que pode parecer em uma primeira impressão, não é esse conteúdo o maior motivo de queixas dos trabalhadores, mas elas se referem à organização do trabalho, as regras impostas para a realização da atividade e a relação com as chefias.

Outro ponto de destaque é a importância do conhecimento do trabalhador para a resolução dos problemas. Em outras palavras, os 
teleatendentes detém o conhecimento necessário não só para o atendimento, mas para apresentar soluções para os problemas do cotidiano, fato ignorado sistematicamente pela direção do centro de urgência e emergências.

Neste sentido, pode-se verificar a importância de metodologias em pesquisas sobre o trabalho que dêem voz aos trabalhadores e as formas como estes solucionam os problemas. Finalmente, não podemos deixar de considerar a importância do gênero da atividade e seu compartilhamento para a realização do trabalho.

\section{CONCLUSÃO}

Foi observado que os fatores geralmente relacionados ao adoecimento nos setores tradicionais do teleatendimento quase não estão presentes nessa central. No entanto, os atendentes vêm manifestando sintomas diversos, além de apresentarem uma rotatividade elevada. Os resultados sugerem que os motivos que têm levado a esse adoecimento podem ser outros, mas parecem estar relacionados com a organização do trabalho.

Um aspecto referente a essa organização do trabalho são as normas que regem o Call Center. As regras são, em determinadas situações, contraditórias e dizem respeito, basicamente, ao comportamento esperado dos teleatendentes, deixando o atendente sem recursos para enfrentar a maior parte dos problemas que se apresentam no seu cotidiano. As regras prescindem de orientações claras para a execução das tarefas, o que resulta no que os teleatendentes denominam de "falta de padronização". Essa "falta de padronização" é um dos principais fatores de desgaste apontados pelos trabalhadores. Eles não têm a autonomia necessária para desenvolver sua atividade, devendo recorrer, nas mais diversas situações, aos supervisores.

Algumas das regras, na visão dos teleatendentes, são vazias de sentido e, por vezes, inconciliáveis com a realidade de trabalho. Como verificado no caso da proibição das "conversas paralelas no local de trabalho", proibição essa que pode impedir o fortalecimento do gênero da atividade (Clot, 2006), já que a comunicação entre eles constitui um recurso essencial para a realização eficiente das tarefas. 
Outro problema decorrente da "falta de padronização" é a insegurança em relação aos casos que não são de competência da instituição. Em diversas situações, existiram divergências nas orientações fornecidas aos teleatendentes. Há uma variação considerável entre as equipes de supervisores sobre quais ocorrências podem ser geradas, o que obriga os atendentes a interromper seu trabalho e consultar o supervisor de plantão.

Seu trabalho, nesses casos, torna-se subordinado à atividade do supervisor, sendo que as instruções oferecidas nem sempre coincidem com a decisão que o atendente tomaria, configurando o que Clot (2006) define como atividade contrariada. Portanto, todas as possibilidades de atuação que foram negadas ou suspensas, continuam pesando sobre a atividade realizada. Esse peso é traduzido por eles como falta de autonomia e de segurança. Caso fosse possível contar com regras mais claras sobre como proceder nessas situações, tais consultas não ocorreriam ou pelo menos seriam drasticamente reduzidas, limitando-se aos casos excepcionais.

Além disso, as escalas de folga dos teleatendentes são insuficientes para o descanso efetivo. As regras dificultam que o trabalhador possa organizar suas folgas para realizar diversas atividades (compromissos escolares, consultas médicas, etc.). O convívio social dos trabalhadores é prejudicado pela organização dessas escalas e alguns teleatendentes há quatro anos trabalham seguidamente nos feriados de final de ano.

O sistema da "seguidinha", criado com a intenção de diminuir o absenteísmo, mostrou-se ineficaz e ao contrário, pode contribuir para o agravamento dos quadros de adoecimento apresentados pelos atendentes. Dessa forma, esse sistema acabou se tornando um instrumento de "presenteísmo", sendo possível pensar que tal medida está alimentando os afastamentos e a rotatividade.

Outras regras contribuem para o presenteísmo e o aumento da rotatividade. Ao proibir a chegada com atraso ou a saída antes do horário para consultas médicas e cercear as permutas entre os colegas, impõe-se uma dificuldade concreta àqueles que dependem do Sistema Único de Saúde (SUS). Restringir essas permutas a apenas duas por teleatendente, no mês, cria dificuldades não apenas para o planejamento de consultas e pequenas viagens, mas também dificulta a vida escolar daqueles que fazem algum 
curso superior que oferecem disciplinas em horários diversos. Enfim, ficam impedidas aquelas pequenas formas de regulação que são essenciais para o cotidiano desses trabalhadores.

Após as observações do trabalho nessa central, pode-se levantar a hipótese de que os principais motivos relacionados aos índices de absenteísmo e adoecimento são: a pouca autonomia na realização do trabalho, a limitação das trocas e as escalas inadequadas que não permitem o descanso efetivo e o convívio social necessário e a imposição do sistema da "seguidinha".

Tal situação pode estar levando alguns teleatendentes ao uso recorrente de medicamentos, entre antidepressivos e ansiolíticos, provavelmente relacionados com quadros de Depressão e Síndrome do Pânico. Apesar do pesquisador não ter tido acesso a dados mais precisos a esse respeito, alguns casos foram verificados durante a pesquisa.

Esses são os principais fatores relacionados ao adoecimento e à rotatividade no setor. Algumas ações podem ajudar a reverter o quadro apresentado, sendo necessário acrescentar que elas resultam do estudo, mas também das trocas estabelecidas com os teleatendentes que se dispuseram a participar: extinção da "seguidinha" e estabelecimento de uma nova escala, com quatro dias trabalhados e dois dias de descanso efetivo; flexibilização das "trocas" de dias e turnos de trabalho entre os teleatendentes; elaboração de uma padronização para os principais casos que geram dúvidas por uma comissão composta por supervisores e teleatendentes; campanha extensiva, através dos meios de comunicações (jornais, revistas e televisão, palestras em escolas) para alertar sobre os problemas gerados pelo trote, com o foco no risco que causa para a população e não apenas baseando-se no custo financeiro.

\section{REFERÊNCIAS}

Agência Nacional de Telecomunicações (1998). Plano Geral de Metas de Qualidade para o Serviço Telefônico Fixo Comutado. Recuperado de: http://www.anatel.gov.br/Portal/exibirPortalInternet.do\# 
Assunção, A. A., \& Vilela, L. V. O. (2004). Os mecanismos de controle da atividade no setor de teleatendimento e as queixas de cansaço e esgotamento dos trabalhadores. Cadernos de Saúde Pública, 20(4), 1069-1078. doi: 10.1590/So102-311X2004000400022

Barreto, F. L. (2001). O sofrimento psíquico e o processo de produção no setor de telefonia: tentativa de compreensão de uma atividade com caráter patogênico (Dissertação de mestrado). Universidade Federal de Minas Gerais, Belo Horizonte.

Canguilhem, G. (2011). O normal e o patológico. Rio de Janeiro, RJ: Forense Universitária. (Obra original publicada em 1966)

Castro, I. S., Campos, N. A., Assunção, A. A., \& Lima, F. P. A. (2006). Diferenças interindividuais em teleatendimento de emergências: explicitação por meio da entrevista de autoconfrontação. Revista Brasileira de Saúde Ocupacional, 31(114), 83-96. doi: 10.1590/ So303-76572006000200008

Chasin, J. (1999). Rota e perspectiva de um projeto marxista. Ensaios Ad Hominem: Revista de Filosofia, Política e Ciência da História, 1(2), 9-81.

Clot, Y. (2006) A função Psicológica do Trabalho. Petrópolis, RJ: Vozes.

Dejours, C. (1987) A loucura do trabalho: estudo de psicopatologia do trabalho. São Paulo, SP: Cortez.

Daniellou, F., Laville, A., \& Teiger, C. (1989). Ficção e realidade do trabalho operário. Revista Brasileira de Saúde Ocupacional, 17(68), 7-13. Recuperado de: https://edisciplinas.usp.br/pluginfile.php/989547/ mod_resource/content/1/Ficcao\%20e\%2orealidade\%20do\%20 trabalho\%20operario\%20-\%20Daniellou\%2C\%20Laville\%20e\%20 Teiger\%201989.pdf

Echternacht, E. H. (2000). Atividades de serviço e lesões por esforços repetitivos: relações mediadas por sistemas informacionais organizados sob princípios tayloristas. In L. I. Sznelwar, \& L. N. Zidan (Orgs.), O trabalho humano com sistemas informatizados no setor de serviços (pp. 149-158). São Paulo, SP: Plêiade. 
Le Guillant, L., Roelens, R., Bégoin, J., Béquart, P., Hamsen, M., \& Lebreton, F. (2006). A neurose das telefonistas. In M. E. A. Lima (Org.), Escritos de Louis Le Guillant - Da ergoterapia à psicopatologia do trabalho (G. Teixeira, Trad.) (pp. 175-188). Petrópolis, RJ: Vozes. (Obra original publicada em 1956)

Lhuilier, D. (2007). Cliniques du travail. Paris, França: Érès.

Lima, M. E. A. (2002). A questão do método em psicologia do trabalho. In I. B. Goulart (Org.), Psicologia Organizacional e do Trabalho: teoria, pesquisa e temas correlatos (pp.123-132). São Paulo, SP: Casa do Psicólogo.

Marinho-Silva, A. (2004). A regulamentação das condições de trabalho no setor de teleatendimento no Brasil: necessidades e desafios. (Dissertação de mestrado). Universidade Federal de Minas Gerais, Belo Horizonte.

Marx, K., \& Engels, F. (1989). A ideologia alemã. São Paulo, SP: Martins Fontes. (Obra original publicada em 1846)

Mascia, F. L., \& Sznelwar, L. I. (2000). Diálogo e constrangimento do script na atividade de atendimento a clientes. In L. I. Sznelwar, \& L. N. Zidan(Orgs.), O trabalho humano com sistemas informatizados no setor de serviços (pp. 97-104). São Paulo, SP: Plêiade.

Ministério do Trabalho e Emprego. (2002). Classificação Brasileira de Ocupações Recuperado de: http://www.mtecbo.gov.br

Ministério do Trabalho e Emprego. (2007). Anexo II da NR-17 - Trabalho em teleatendimento/telemarketing. Recuperado de: http://trabalho. gov.br/images/Documentos/SST/NR/NR17-ANEXO2.pdf

Ministério do Trabalho e Emprego. (2017). Perfil do Município. Recuperado de: http://bi.mte.gov.br/bgcaged/caged_perfil_municipio/index.php Oliveira, S., \& Jacques, M. G. C. (2006). Políticas e práticas de Gestão e saúde: recortes sobre o trabalho de teleatendimento no Rio Grande do Sul. Revista Brasileira de Saúde Ocupacional, 31(114), 63-72. doi: 10.1590/So303-76572006000200006 
Pacheco, V. G. (2002). Gênero, saúde e trabalho: fatores que interagem no desenvolvimento de L.E.R. em trabalhadores telefônicos. (Dissertação de mestrado). Universidade Federal de Minas Gerais, Belo Horizonte.

Rechenberg, L., Goulart, B. N. G., \& Roithmann, R. (2011). Impacto da atividade laboral de teleatendimento em sintomas e queixas vocais - estudo analítico. Jornal Sociedade Brasileira de Fonoaudiologia, 23(4), 301-307. doi: 10.1590/S2179-64912011000400003

Ricci, M. G., \& Rachid, A. (2013). Relações de trabalho no serviço de teleatendimento. Gestão da Produção, 2O(1), 192-203. Recuperado de: http://www.scielo.br/pdf/gp/v2on1/a14v2on1.pdf

Sznelwar, L. I., \& Masseti, M. (2000). Sofrimento no trabalho: uma leitura a partir de grupos de expressão. In L. I. Sznelwar, \& L. N. Zidan (Orgs.), O trabalho humano com sistemas informatizados no setor de serviços (pp. 105-117). São Paulo, SP: Plêiade.

Tribunal Superior do Trabalho. (2002). Orientação Jurisprudencial $n^{o}$ 273. Recuperado de: https://www.jurisway.org.br/v2/sumula. asp?idmodelo $=3006$

Venco, S. (2008). Quando o trabalho adoece: uma análise sobre o teleatendimento. InterfacEHS, 3(3), 1-18. Recuperado de: http:// www3.sp.senac.br/hotsites/blogs/InterfacEHS/wp-content/ uploads/2013/07/art-1-2008-3.pdf

Vilela, L. V. O. (2002). As condições de adoecimento na Empresa Contaxestudo ergonômico (Dissertação de mestrado). Universidade Federal de Minas Gerais, Belo Horizonte. 